\title{
Anxiety and depression risk in patients with allergic rhinitis: a systematic review and meta-analysis*
}

\author{
J. Rodrigues 1,2,3, F. Franco-Pego ${ }^{3,4}$, B. Sousa-Pinto ${ }^{3,4}$, J. Bousquet ${ }^{5,6,7}$, \\ K. Raemdonck ${ }^{2,3,8}$, R. Vaz ${ }^{1,2,3}$ \\ Rhinology 59: 4, 360 - 373, 2021 \\ https://doi.org/10.4193/Rhin21.087 \\ 'Otorhinolaryngology Department, Centro Hospitalar Universitário de S. João, EPE, Porto, Portugal. \\ *Received for publication: \\ 2 Unit of Anatomy, Department of Biomedicine, Faculty of Medicine, University of Porto, Porto, Portugal \\ March 7, 2021 \\ ${ }^{3}$ CINTESIS - Center for Health Technology and Services Research, University of Porto, Porto, Portugal. \\ Accepted: May 26, 202 \\ ${ }^{4}$ MEDCIDS - Department of Community Medicine, Information and Health Decision Sciences; Faculty of Medicine, University of \\ Porto, Porto, Portugal. \\ ${ }^{5}$ Charité, Universitätsmedizin Berlin, Humboldt-Universität zu Berlin, Berlin, Germany. \\ ${ }^{6}$ Comprehensive Allergy Center, Department of Dermatology and Allergy, Berlin Institute of Health, Berlin, Germany. \\ MACVIA-France, Montpellier, France. \\ ${ }^{8} \mathrm{CESPU}$ - Institute of Research and Advanced Training in Health Sciences and Technologies (IINFACTS), Gandra, Portugal
}

\begin{abstract}
Background: Allergic diseases appear to be associated with mood disorders. However, particularly regarding allergic rhinitis (AR), such association has not been adequately systematically reviewed. Therefore, we conducted a systematic review and meta-analysis to quantify the association between AR and depression and anxiety.
\end{abstract}

Methodology: We performed an electronic search of PubMed, Web of Science and Scopus for observational studies assessing the association between AR and depression and anxiety. Such association was quantified by means of random-effects meta-analysis, with estimation of pooled odds ratio (OR). Sources of heterogeneity were explored by subgroup analysis.

Results: We included a total of 24 primary studies, of which 23 assessed depression and 11 assessed anxiety. Of these, 12 studies presented OR from multivariable regression models and were included in our meta-analysis. AR was associated with higher odds of depression and anxiety.

Conclusions: AR appears to be associated with high risk of depression and anxiety. While our results point to the importance of mental comorbidities among patients with $A R$, longitudinal studies are needed adopting uniform definitions and presenting results stratified by AR severity.

Key words: allergic rhinitis, allergy, anxiety, depression, mental health

\section{Introduction}

Allergic rhinitis (AR) affects more than 400 million people worldwide $^{(1)}$. In Europe, its prevalence is approximately $25 \%$, being even higher in urban areas ${ }^{(1,2)}$. Allergic rhinitis and its comorbidities are often overlooked, underdiagnosed and undertreated $^{(3)}$. In fact, despite not being a life-threatening disease, AR has important consequences on health and well-being, being associated with disruption of sleeping patterns $s^{(4)}$, cognitive and performance impairment ${ }^{(5,6)}$ and decrease in quality of life ${ }^{(7)}$ and work and school performance ${ }^{(5,8)}$. In addition, AR may also be associated with higher risk for psychiatric disease - mental illness was found to be associated with several chronic diseases, including chronic respiratory diseases. An association between allergic disorders (asthma, rhinitis and dermatitis) and mental illness has been identified, especially in mood disorders such as depression and anxiety ${ }^{(9,10)}$. Furthermore, depressive symptoms have also been correlated with seasonality and severity of allergy ${ }^{(11)}$. Asthma is the allergic disorder for which there have been more studies establishing an association with the development of mental illness. In fact, a previous systematic review 
has found that asthmatic patients have a risk 2.1 times higher of developing depression and a risk 1.8 times higher of developing anxiety when compared to those without asthma ${ }^{(12)}$. Although it is possible that a similar association with mood disorders can also be found in AR, such association has not been systematically reviewed in a fully dedicated study to this research question. The aim of this study is to systematically review the literature to assess and quantify the association between AR and depression and anxiety. In addition, we aimed to identify variables potentially explaining heterogeneity across studies.

\section{Materials and methods}

\section{Eligibility criteria and search strategy}

This review was conducted in accordance with the Preferred Reporting Items for Systematic reviews and Meta-Analyses (PRISMA) statement and with the Cochrane Handbook for Systematic Reviews ${ }^{(13,14)}$. We included observational studies comparing patients with diagnosed $A R$ versus those without $A R$ on the frequency of depression and/or anxiety. Case reports, reviews and editorials were excluded.

Our search was performed in three electronic databases - PubMed, Web of Science and Scopus -, in March 2020. Research on electronic databases was complemented with manual review of the references in the included primary studies. No date or language restrictions were applied.

\section{Study selection and data extraction}

After duplicates removal, two authors (JR and FFP) independently screened all titles and abstracts of the studies obtained from database searches. Subsequently, the full texts of selected studies were retrieved and independently read by two authors (JR and FFP), who extracted data on the year of publication, country of study, study design, average age, percentage of female subjects, frequency of asthma and atopic dermatitis, percentage of urban dwellers, AR definition and method of assessment, depression/anxiety definition and method of assessment, number of subjects with and without AR, frequency of depression and anxiety in each group and adjusted effect size measures. Countries where the study was performed were grouped into three regions - Europe, USA and Far East. Concerning AR assessment, studies were classified into those in which AR 1) was clinically diagnosed when the study was being performed, 2) had been previously registered by a healthcare professional (i.e., information on AR was obtained by consulting patients' clinical files), or 3) was simply reported by the patient. We also classified primary studies according to the method of outcome assessment (either depression or anxiety), into those in which 1) a previous diagnosis had been registered by a healthcare professional (i.e., information on depression/anxiety was obtained by consulting participants' clinical files); 2) validated questionnaires were applied, or 3) symptoms or a previous diagnosis had sim- ply been reported by the patient without the use of validated questionnaires. We used a purposely-built form to extract data. We developed a pilot version which was modified after assessment of the first 10 studies.

Any disagreement between authors was solved by consensus and, if not reached, by discussion with a third author (BSP). Data missing from the primary studies was requested by contacting the authors. Duplicate or overlapping reports were identified, privileging the ones with more complete results.

\section{Quality assessment}

An adapted version of The National Health Institute (NIH) Quality Assessment Tool for Observational Cohort and Cross-Sectional Studies was used to evaluate the included primary studies ${ }^{(15)}$. The tool consists of 14 items with "Yes/No" answers. Question number 8 , inquiring if the study examines different exposure levels and their relation with the outcome, was not answered for any study due to the dichotomous format of the data retrieved. For cross-sectional studies, no answers were registered for questions $6,7,10,12$ and 13, as such questions would not be applicable. The two authors (JR and FFP) independently assessed the quality of each study, with any disagreement being solved by consensus.

\section{Data analysis}

As our main analysis, we performed meta-analysis assessing the associations between AR and anxiety and depression, based on adjusted odds ratios (ORs) (i.e., OR obtained with multivariable regression models) retrieved from included primary studies. Whenever primary studies applied more than one multivariable model, we retrieved the results obtained with the model adjusting for the largest number of independent variables. In order to assess results consistency, we also performed meta-analysis for the crude associations between AR and anxiety/depression, by pooling raw data retrieved from included primary studies. For those studies only providing effect size measures and the respective confidence intervals, raw data was estimated using the methods described by Di Pietrantonj and using estimraw interactive tool ${ }^{(16,17)}$.

Pooled ORs were estimated by means of random-effects metaanalysis, with weighting by the restricted maximum likelihood approach. In each meta-analysis, we only included primary studies with the same design (i.e., we did not include crosssectional and cohort studies in the same analyses). Betweenstudy heterogeneity was assessed using the $I^{2}$ statistic and the Cochran Q statistic. An $\mathrm{I}^{2}>50 \%$ and a Cochran $Q$ statistic P value $<0.1$ were considered to represent substantial heterogeneity. In order to identify variables that could explain such differences across primary studies' results, we performed subgroup analyses. Subgroup analyses were based on the types of covariates included in multivariable models, as well as on the study region, 


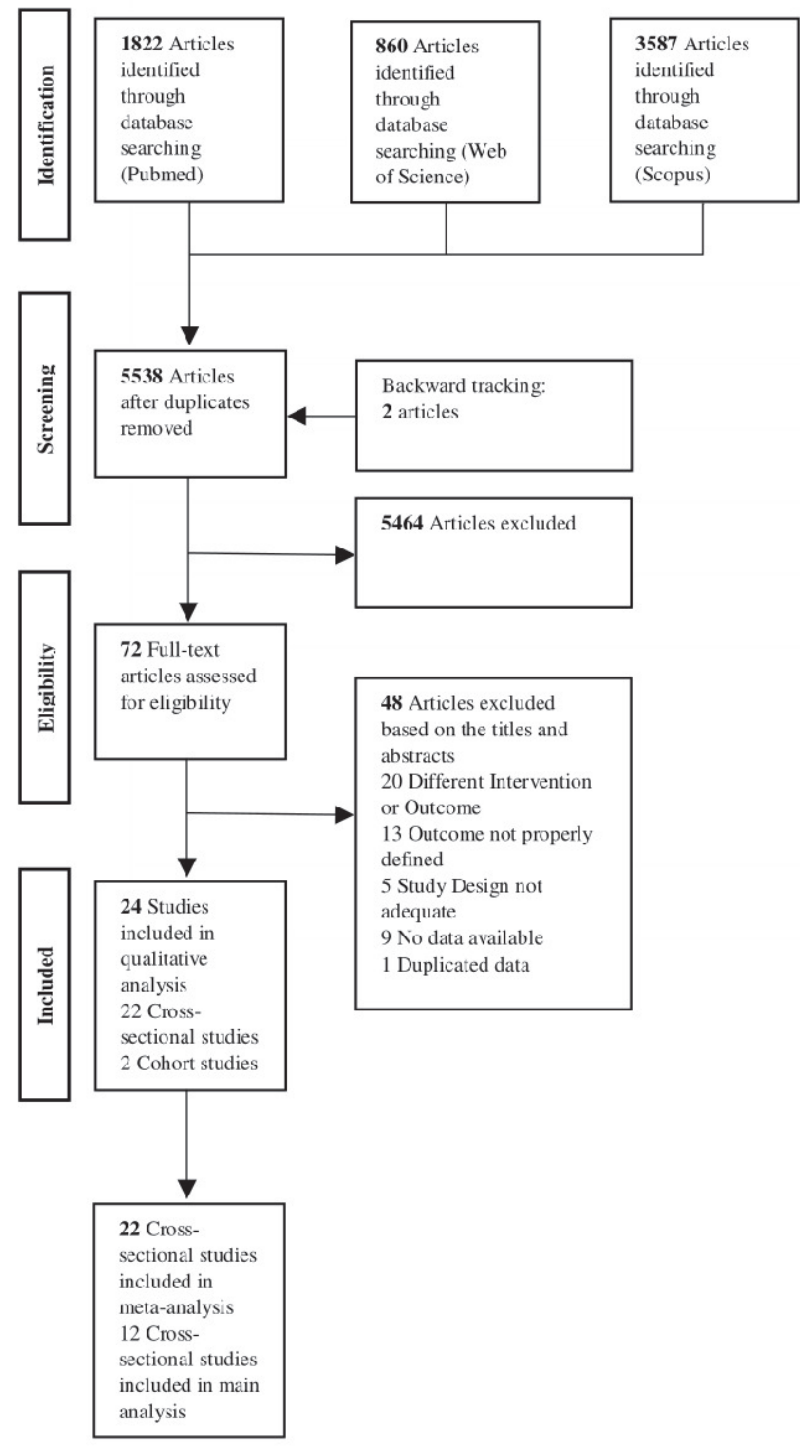

Figure 1. PRISMA Flow Diagram showing search strategy and studies selection.

participants' age group and methods of exposure and outcome assessment (as defined in the Data Extraction section). Metaregression was not performed within our main analyses on account of the insufficient number of included primary studies in the analysis for which substantial heterogeneity was found, but was performed in the ancillary analyses using raw data. Publication bias was assessed by observation of funnel plots and trim-and-fill analysis for each outcome. Data analysis was performed using software R (version 4.0), with use of the metafor package.

\section{Results}

\section{Study selection}

The study selection process is illustrated in Figure 1. We retrieved a total of 6269 citations from electronic databases and
2 additional citations from reference consultation of included primary studies. After duplicates removal and initial title and abstract screening, 72 studies were identified for full-text review. Of these, we were not able to assess 8 studies, as full papers were not available even after contacting the authors $(n=6)$, or no information in English was provided after contacting the authors $(n=2)$. Forty studies were further excluded after full-text reading, leaving 24 primary studies included in the systematic review $^{(18-41)}$. Among the included papers, 13 studies solely reported results on depression ${ }^{(19,21-23,28-32,36,37,39,41)}$, one study solely reported results on anxiety ${ }^{(35)}$ and 10 studies presented results on both depression and anxiety ${ }^{(18,20,24-27,33,34,38,40)}$. Of these 24 primary studies, 12 studies ${ }^{(2,206-30,34-36,38,39,41)}$ presented OR from multivariable regression models and were included in our main analyses - 11 studies $^{(20,26-30,34,36,38,39,41)}$ provided results from multivariable models assessing the association between AR and depression, while 6 studies ${ }^{(20,26,27,34,35,38)}$ provided results from multivariable models assessing the association between AR and anxiety ( 5 studies $^{(20,26,27,34,38)}$ provided information on both depression and anxiety).

\section{Studies characteristics}

Table 1 summarizes the characteristics of the 23 included primary studies assessing the association between AR and depression ${ }^{(18-34,36-41)}$. These studies were published between 1991 and 2019 and their sample sizes ranged from 88 to 240 million participants, resulting in a total of more than 243 million participants. Twenty-one studies had a cross-sectional design $^{(18-21,23-33,36-41)}$, while two consisted of cohort studies ${ }^{(22,34)}$. Eleven studies were conducted in America ${ }^{(19-21,24-27,29,35,36,41)}, 7$ in Europe $\mathrm{e}^{(18,28,32,33,37,38,40)}$ and 5 in Asia ${ }^{(22,23,30,31,39)}$. Thirteen studies included only adults $(18,20,21,27-30,33,35-37,39-41), 6$ included only children/adolescents ${ }^{(19,22,23,26,31,34)}$ and 4 included participants of both age groups $\mathrm{s}^{(24,25,32,38)}$. Allergic rhinitis diagnosis was performed by a physician at the time of assessment in 6 studies $^{(18-20,28,34,40)}$, obtained by consulting the clinical file in 4 studies $^{(22,24,37,38)}$ and reported by the patient in 13 studies $^{(21,23,25-27,29-33,36,39,41)}$. Depression was evaluated by a validated questionnaire in 12 stu$\operatorname{dies}^{(18-21,27-29,32-34,36,38)}$, self-reported in 7 studies ${ }^{(23,25,26,30,31,39,41)}$ and assessed by consulting clinical files in 4 studies $^{(22,24,37,38)}$. In our main meta-analysis, we included a total of $19,220,087$ participants with AR and depression was identified in 3,939,572 of them, corresponding to a frequency of $20.5 \%$ (range $0.6-38.7 \%$ ). These studies also included a total of 222,648,239 participants without $A R$, of whom $36,941,336$ had depression, corresponding to a frequency of $16.6 \%$ (range $0.2-16.7 \%$ ).

Table 2 presents details of the 11 studies examining the possible association between AR and anxiety ${ }^{(18,20,24-27,33-35,38,40)}$. These studies were published between 1999 and 2019 and their sample sizes ranged from 88 to $1,750,000$, resulting in a total of more than 2 million of participants included in this analysis. 
Table 1. Characteristics of primary studies assessing depression in patients with allergic rhinitis (AR).

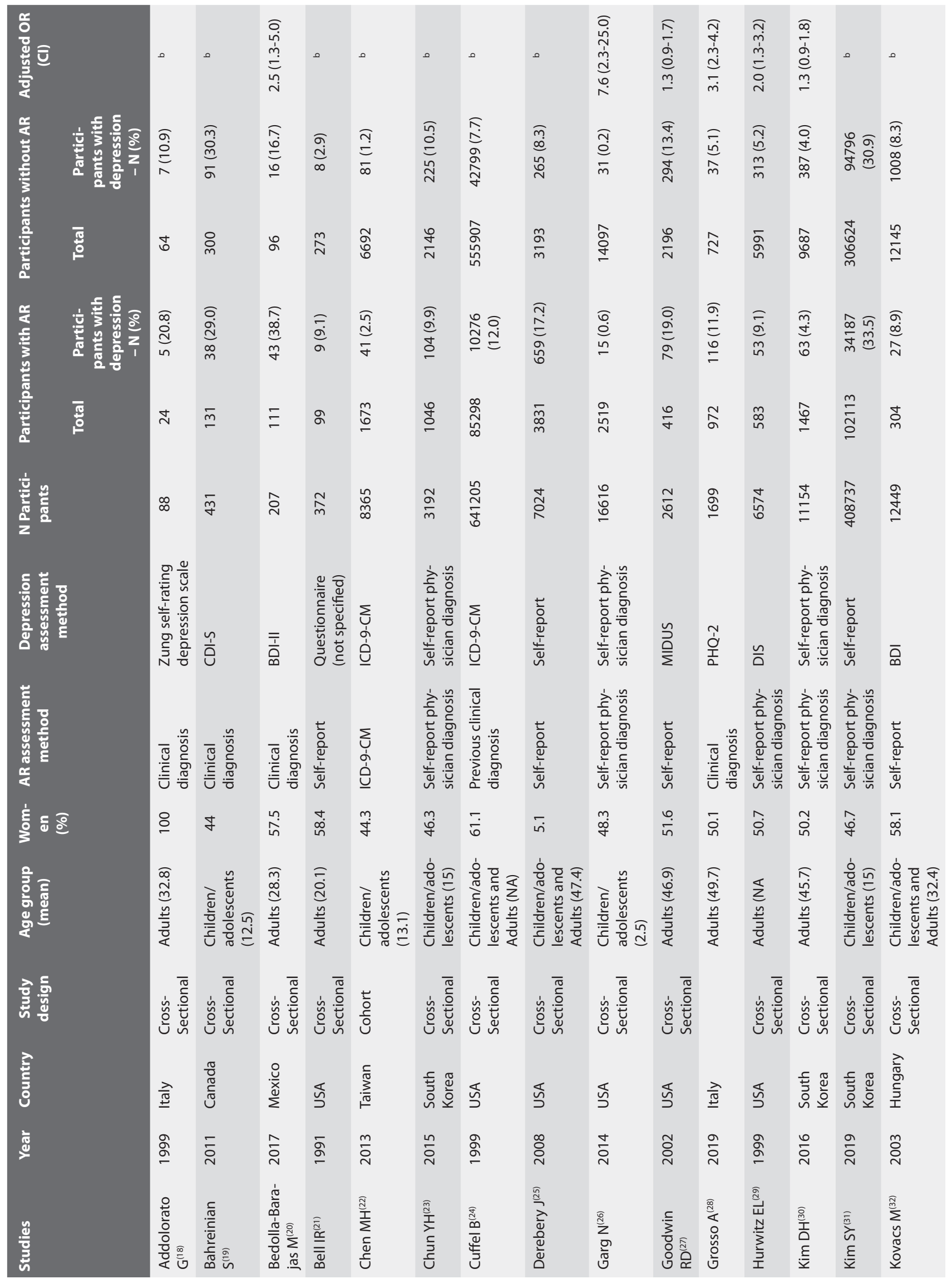




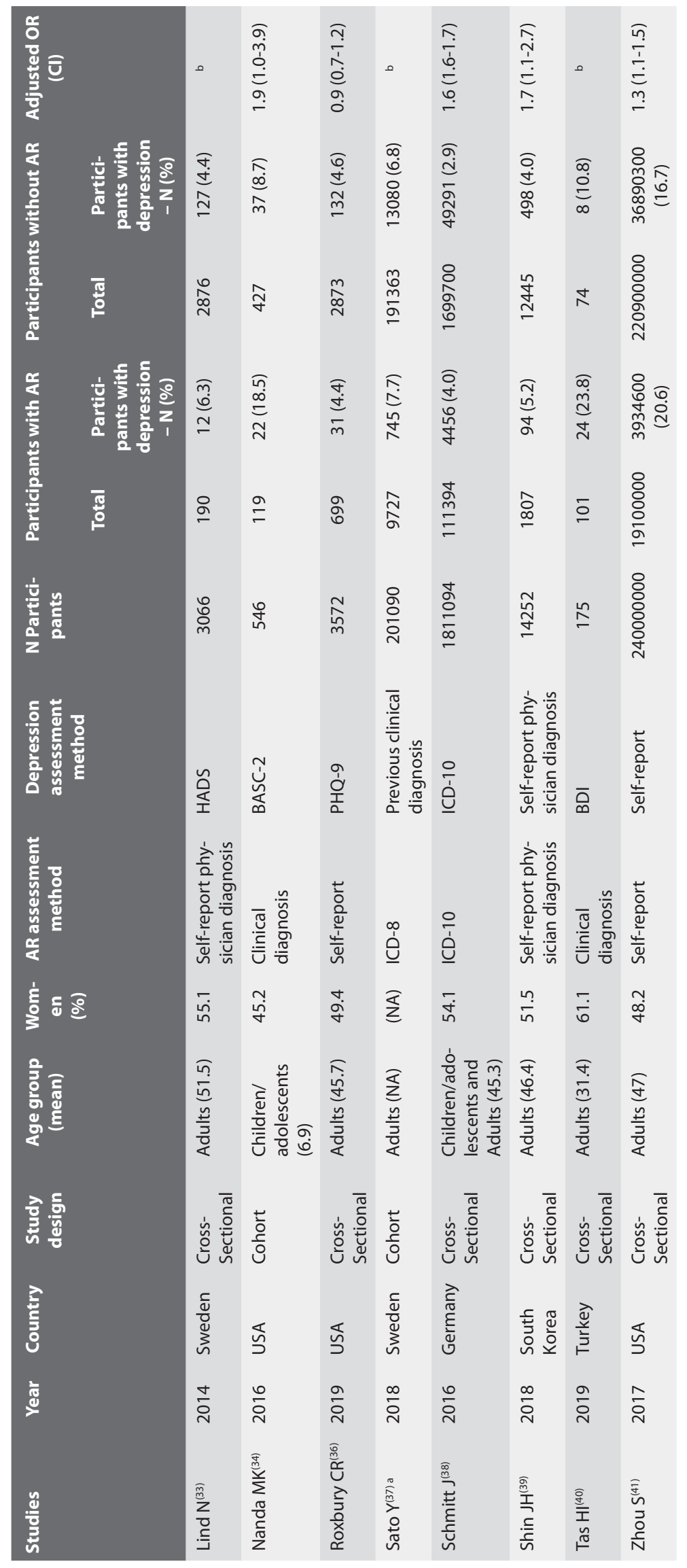

Abbreviations: BASC-2, Behaviour Assessment System for Children, Second Edition; BDI, Beck Depression Inventory; BDI-II, Beck Depression Inventory-II; CDI-S, Children's Depression Inventory Short Form; DIS, Diagnostic Interview Schedule; HADS, Hospital Anxiety and Depression Scale; ICD8, International Classification of Diseases, Eight Revision; ICD9-CM, International Classification of Diseases, Ninth Revision, Clinical Modification; ICD-10, International Classification of Diseases, Tenth Revision; MIDUS, Midlife Development in the United States; NA - not available; PHQ-2, Patient Health Questionnaire-2; PHQ-9, Patient Health Questionnaire-9; a Cohort study considered as cross-sectional despite being a cohort due to the format of the available data; ${ }^{b}$ Adjusted OR not presented in primary study. 


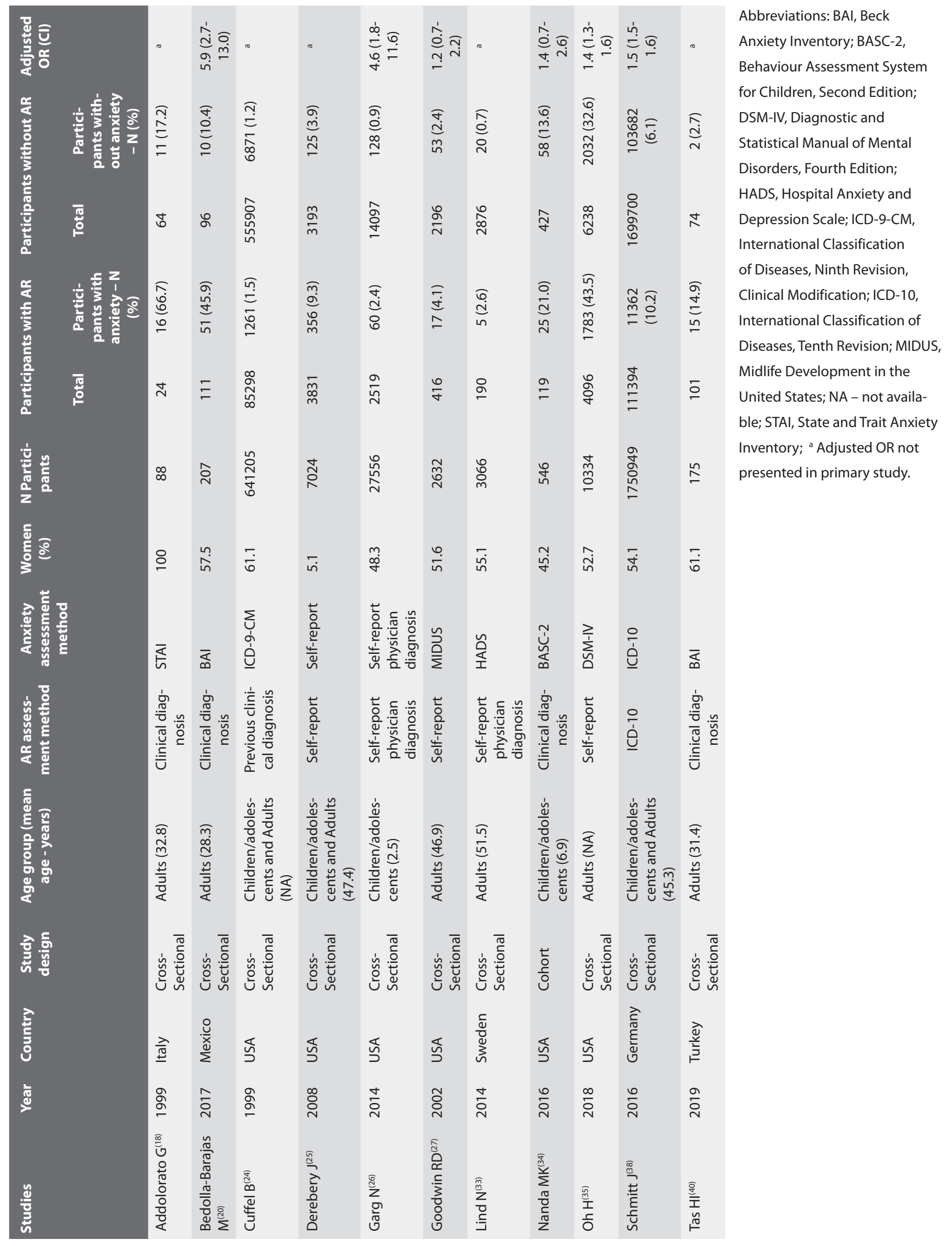




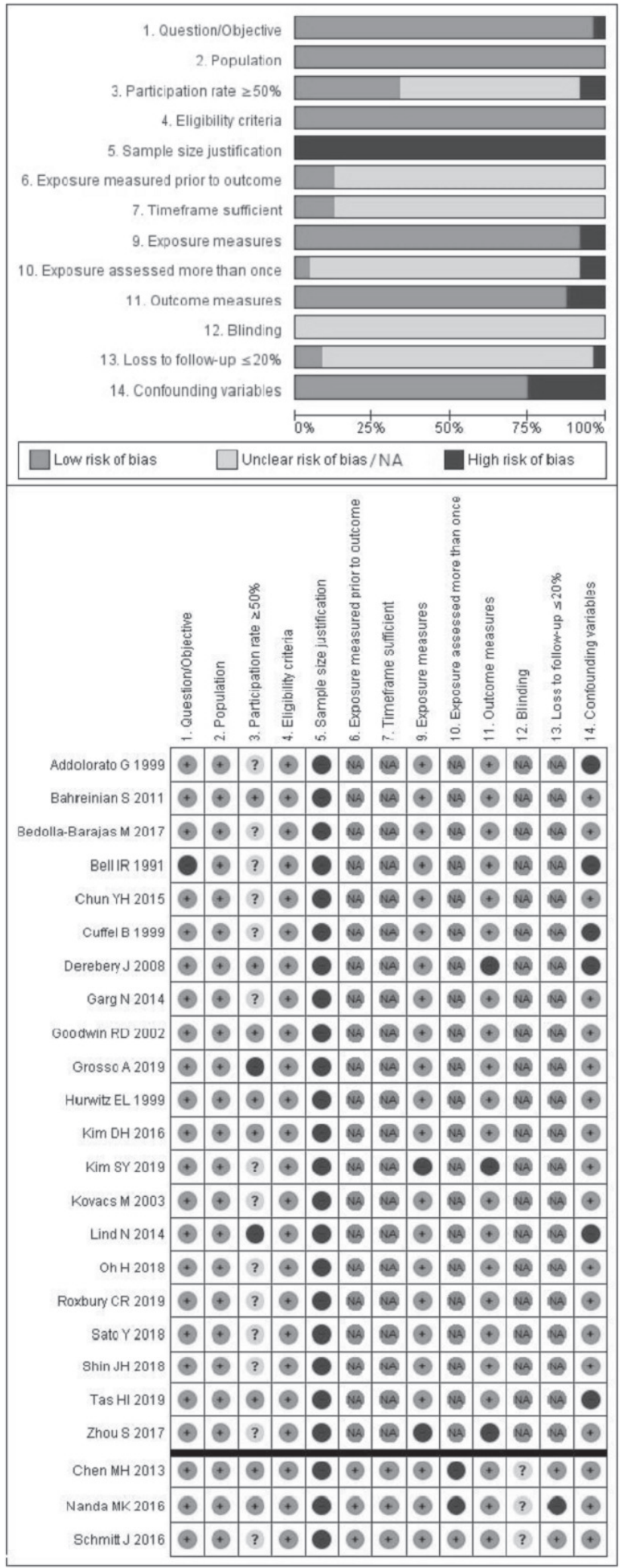

Figure 2. Risk of bias graph and risk of bias summary.

Ten studies had a cross-sectional design ${ }^{(18,20,24-27,33,35,38,41)}$, with the other one consisting of a cohort study ${ }^{(34)}$. Seven studies were conducted in America ${ }^{(20,24-27,34,35)}$ and 4 in Europe ${ }^{(18,33,38,41)}$. Six studies included only adults $(18,20,27,33,35,41), 2$ included only children $^{(26,34)}$ and 3 included both age groups ${ }^{(24,25,38)}$. Allergic rhinitis

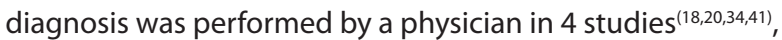
previously registered by a in the clinical files in 2 studies ${ }^{(24,38)}$ and self-reported in the remaining 5 studies ${ }^{(25-27,33,35)}$. Anxiety was previously registered by in clinical files in 3 studies $^{(24,35,38)}$, determined by questionnaire in 6 studies $^{(18,20,27,33,34,41)}$ and self-reported in 2 studies $^{(25,26)}$. In our main meta-analysis, we included a total of 118,655 participants with AR and anxiety was identified in 13,298 of them, corresponding to a frequency of $11.2 \%$ (range 2.4-45.9\%). On the other hand, anxiety was detected in only 105,963 of the $1,722,754$ participants without $A R$, corresponding to a frequency of $6.2 \%$ (range $0.9-32.6 \%$ ).

\section{Quality assessment}

No studies complied with all quality items in the NIH Quality Assessment Tool. Two cohort studies ${ }^{(22,34)}$ complied with 10 and one ${ }^{(38)}$ with 9 items out of 13 . The cross-sectional studies complied with between 4 and 7 quality items out of 8 (median of 6 items). None of the studies presented a sample size justification, four did not adjust for confounding and three did not have clearly defined outcome measures (Figure 2).

\section{Meta-analytic association between AR and Depression} We performed a random-effects meta-analysis on the association between AR and depression, including the 11 primary studies with a cross-sectional design and with available adjusted OR (Figure 3). The number of cohort studies was too small for meta-analytical evaluation. We found that patients with AR presented with a higher chance of depression when compared to healthy controls (pooled meta-analytical OR $=1.61 ; 95 \% \mathrm{Cl}=1.32$ 1.96; $P<0.001 ; I^{2}=0 \% Q$-Cochran $p$-value $=0.34$ ) (Table 3 ).

Consistent results were observed in subgroup analysis, with all except two analyses resulting in significant positive associations between AR and depression, with low-moderate heterogeneity. In particular, in subgroup analyses according to the method of AR assessment, we identified similar associations between AR diagnosed by self-report or clinical diagnosis, with low heterogeneity $\left(O R=1.40 ; 95 \% C l=1.04-1.89 ; P<0.026 ; I^{2}=0 \%\right.$ vs $O R=1.95$; $\left.95 \% \mathrm{Cl}=1.32-2.87 ; \mathrm{P}<0.001 ; \mathrm{I}^{2}=23 \%\right)$. This association was also similar among the different methods of depression diagnosis (self-report: $\mathrm{OR}=1.86 ; 95 \% \mathrm{Cl}=1.10-3.13 ; \mathrm{P}<0.020 ; \mathrm{I}^{2}=37 \%$; questionnaire: $\mathrm{OR}=1.48 ; 95 \% \mathrm{Cl}=1.04-2.09 ; \mathrm{P}<0.028 ; \mathrm{I}^{2}=0 \%$; previous clinical diagnosis: $(\mathrm{OR}=1.61 ; 95 \% \mathrm{Cl}=1.20-2.15 ; \mathrm{P}<0.001)$. We also performed a sensitivity analysis excluding the largest included study (Zhou et al.)(41), which had also important methodological limitations (namely the assessment of AR and anxiety/ depression by self-reporting) - we observed a pooled $\mathrm{OR}=1.66$ $(95 \% \mathrm{Cl}=1.34-2.04 ; \mathrm{P}<0.001)$, with no detectable heterogeneity $\left(I^{2}=0 \%\right.$ Q-Cochran p-value=0.30) (Supplementary Table 1). Meta-analytical evaluation of the raw data retrieved from inclu- 


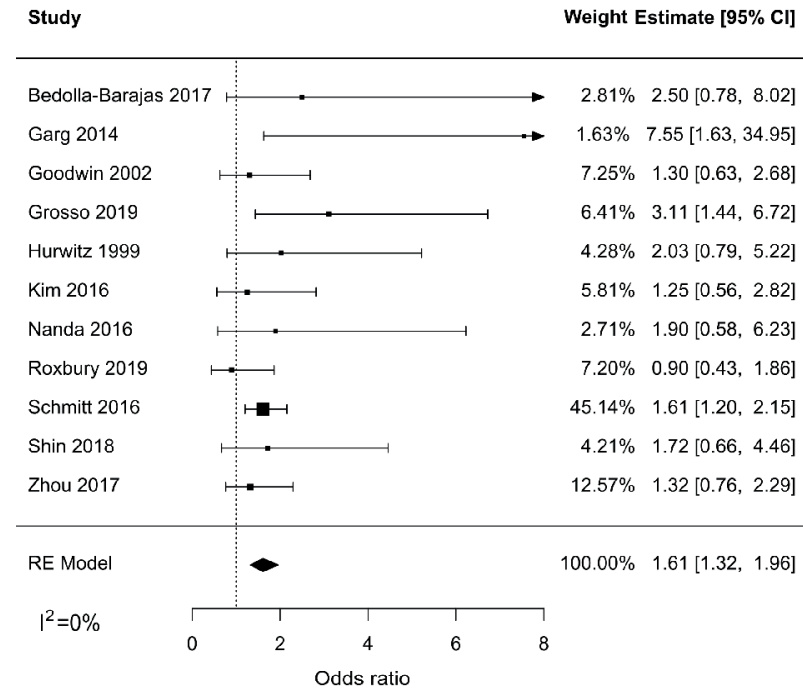

Figure 3. Forest Plot showing the meta-analytic estimate for the association between allergic rhinitis and depression.

\begin{tabular}{|c|c|c|c|}
\hline Study & & & Weight Estimate $[95 \% \mathrm{Cl}]$ \\
\hline Bedolla-Barajas 2017 & & $\longrightarrow$ & $13.53 \% 5.90[2.68,13.00]$ \\
\hline Garg 2014 & & $\rightarrow$ & $11.79 \% \quad 4.56[1.79,11.59]$ \\
\hline Goodwin 2002 & 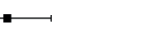 & & $16.00 \% \quad 1.20[0.65,2.20]$ \\
\hline Nanda 2016 & & & $15.81 \% \quad 1.40[0.75,2.60]$ \\
\hline Oh 2018 & $=$ & & $21.27 \% \quad 1.43[1.25,1.63]$ \\
\hline Schmitt 2016 & - & & $21.60 \% \quad 1.52[1.48,1.56]$ \\
\hline RE Model & - & & $100.00 \% \quad 1.95[1.21,3.14]$ \\
\hline \multirow[t]{2}{*}{$1^{2}=97 \%$} & 1 & 1 & \\
\hline & 4 & 6 & \\
\hline
\end{tabular}

Figure 4. Forest Plot showing the meta-analytic estimate for the association between allergic rhinitis and anxiety.

ded primary studies supported higher chance of depression in patients with AR when compared to healthy controls (pooled meta-analytical $\mathrm{OR}=1.40 ; 95 \% \mathrm{Cl}=1.30-1.52$ ), although severe heterogeneity was detected $\left(I^{2}=98 \%, P<0.001\right)$ (Table 4$)$.

Meta-analytic association between AR and anxiety The meta-analysis on the association between AR and anxiety included 6 cross-sectional primary studies with available adjusted OR (Figure 4). We found that AR was associated with higher frequency of anxiety, although severe heterogeneity was detected (pooled $\mathrm{OR}=1.91 ; 95 \% \mathrm{Cl}=1.21-3.02 ; \mathrm{P}=0.005 ; \mathrm{I}^{2}=97 \%$ ). However, no heterogeneity was detected in subgroup analysis of studies whose models included demographic variables $\left(\mathrm{OR}=1.52 ; 95 \% \mathrm{Cl}=1.48-1.55 ; \mathrm{P}<0.001 ; \mathrm{I}^{2}=0 \%\right)$, for those which adjusted simultaneously for demographic and socioeconomic variables and comorbidities/habits $(\mathrm{OR}=1.45 ; 95 \% \mathrm{Cl}=1.28-1.64$; $\mathrm{P}<0.001 ; \mathrm{I}^{2}=0 \%$ ) (Table 5 ). In subgroup analyses performed by the method of AR assessment, we identified similar associations between $A R$ diagnosed by self-report or clinical diagnosis $\left(\mathrm{OR}=1.78 ; 95 \% \mathrm{Cl}=0.91-3.49 ; \mathrm{P}<0.092 ; \mathrm{l}^{2}=79 \%\right.$ vs $\mathrm{OR}=2.19$; $\left.95 \% \mathrm{Cl}=0.94-5.12 ; \mathrm{P}<0.069 ; \mathrm{I}^{2}=89 \%\right)$. This association was also similar among the different methods of anxiety diagnosis (selfreport: $\mathrm{OR}=2.15 ; 95 \% \mathrm{Cl}=0.90-5.16 ; \mathrm{P}<0.085 ; \mathrm{I}^{2}=89 \%$; questionnaire: $\mathrm{OR}=2.23 ; 95 \% \mathrm{Cl}=0.60-8.21 ; \mathrm{P}<0.229 ; \mathrm{I}^{2}=82 \%$; previous clinical diagnosis: $(\mathrm{OR}=1.52 ; 95 \% \mathrm{Cl}=1.48-1.56 ; \mathrm{P}<0.001)$. Meta-analysis of the raw data retrieved from included primary studies sustained higher chance of anxiety in patients with AR when compared to healthy controls (pooled meta-analytical $\left.\mathrm{OR}=2.10 ; 95 \% \mathrm{Cl}=1.73-2.56 ; \mathrm{P}<0.001 ; \mathrm{I}^{2}=95 \%\right)$, although severe heterogeneity was detected $\left(I^{2}=98 \%, P<0.001\right)$ (Table 4).

\section{Analysis of publication bias}

The funnel plots (Figure 5) displayed an asymmetrical pattern, being suggestive of publication bias in favour of studies reporting positive associations between AR and depression/anxiety. The trim-and-fill analysis estimated three missing studies for the association between AR and depression - if those studies were included in the meta-analysis, a pooled OR of 1.45 would have been observed $\left(95 \% \mathrm{Cl}=1.15-1.82 ; \mathrm{p}=0.002 ; \mathrm{I}^{2}=17 \%\right)$. No missing studies were estimated in trim-and-fill analysis for the association between AR and anxiety.

\section{Discussion}

In this systematic review, we assessed the association between $\mathrm{AR}$ and the presence of depression and anxiety, two common mental disorders. We observed, by means of meta-analysis, that patients with AR have 1.6 times more chances to present depression and 1.9 times to more chances to present anxiety. We performed a meta-analytic evaluation including studies with adjusted ORs and we found a statistically significant association between AR and depression, comparing with healthy controls, with no heterogeneity being detected. Concerning anxiety, adjusted ORs obtained with multivariable regression models also demonstrated a positive association between AR and anxiety, with no heterogeneity being detected in subgroup analyses of studies adjusting for a larger set of covariates.

Our results are compatible to those of a recent systematic review that demonstrated higher risk of depression in allergic patients ${ }^{(42)}$. While in that study the authors performed a subgroup analysis on AR (identifying a positive link between AR and depression), such analysis included only 5 studies, it did not assess anxiety as an outcome variable and was not undertaken as a primary aim of the study and all the involving analysis we perform in this study.

The pathophysiologic mechanisms underlying the association between depression/anxiety and AR may be similar to those observed in asthma, which has also been associated with increased risk of depression ${ }^{(12,43)}$. Such mechanisms include increased 
Table 3. Meta-analytical results and results of the subgroup analyses on the association between allergic rhinitis and depression.

\begin{tabular}{|c|c|c|c|}
\hline & \multirow[t]{2}{*}{ N studies } & \multicolumn{2}{|c|}{ Subgroup analysis } \\
\hline & & OR (95\%CI) [p-value] & $\begin{array}{c}\text { Heterogeneity }-\mathbf{I}^{\mathbf{2}} ; \\
\mathbf{p} \text {-value }\end{array}$ \\
\hline All studies & 11 & $1.61(1.32-1.96)[<0.001]$ & $0 \% ; 0.341$ \\
\hline $\begin{array}{l}\text { Variables adjusted for in multivariable models }{ }^{\text {a }} \\
\text { Demographic variables } \\
\text { Demographic and socioeconomic variables } \\
\text { Demographic variables and comorbidities/habits } \\
\text { Demographic and socioeconomic variables and comorbidities/habits }\end{array}$ & $\begin{array}{l}10 \\
7 \\
7 \\
5\end{array}$ & $\begin{array}{l}1.58(1.30-1.94)[<0.001] \\
1.73(1.25-2.40)[0.001] \\
1.69(1.11-2.57)[0.014] \\
1.95(1.20-3.18)[0.007]\end{array}$ & $\begin{array}{l}0 \% ; 0.300 \\
11 \% ; 0.238 \\
35 \% ; 0.127 \\
33 \% ; 0.148\end{array}$ \\
\hline $\begin{array}{l}\text { Region } \\
\text { USA } \\
\text { Europe } \\
\text { Far East }\end{array}$ & $\begin{array}{l}6 \\
2 \\
2\end{array}$ & $\begin{array}{l}1.43(1.03-1.98)[0.033] \\
2.02(1.09-3.73)[0.025] \\
1.43(0.77-2.65)[0.255]\end{array}$ & $\begin{array}{c}0 \% ; 0.222 \\
59 \% ; 0.118 \\
0 \% ; 0.620\end{array}$ \\
\hline $\begin{array}{l}\text { Age group } \\
\text { Children and adolescents } \\
\text { Adults }\end{array}$ & $\begin{array}{l}3 \\
3\end{array}$ & $\begin{array}{l}1.52(1.15-2.02)[0.031] \\
2.15(1.05-4.42)[0.035]\end{array}$ & $\begin{array}{c}4 \% ; 0.423 \\
45 \% ; 0.149\end{array}$ \\
\hline $\begin{array}{l}\text { Method of rhinitis assessment } \\
\text { Self-report } \\
\text { Clinical diagnosis }\end{array}$ & $\begin{array}{l}7 \\
4\end{array}$ & $\begin{array}{l}1.40(1.04-1.89)[0.026] \\
1.95(1.32-2.87)[0.001]\end{array}$ & $\begin{array}{c}0 \% ; 0.322 \\
23 \% ; 0.423\end{array}$ \\
\hline $\begin{array}{l}\text { Method of depression assessment } \\
\text { Self-report } \\
\text { Questionnaire } \\
\text { Previous clinical diagnosis }\end{array}$ & $\begin{array}{l}5 \\
5 \\
1\end{array}$ & $\begin{array}{l}1.86(1.10-3.13)[0.020] \\
1.48(1.04-2.09)[0.028] \\
1.61(1.20-2.15)[0.001]\end{array}$ & $\begin{array}{l}37 \% ; 0.216 \\
0 \% ; 0.298 \\
-b\end{array}$ \\
\hline
\end{tabular}

$\mathrm{Cl}=$ Confidence interval; $\mathrm{OR}=$ Odds Ratio; ${ }^{\text {a }}$ One study did not specify the variables for which adjustments were performed in multivariable models. Adjusting for demographic variables implies adjusting for at least one of the following: sex, age, ethnicity, marital status or region; adjusting for socioeconomic variables implies adjusting for at least one of the following: education, parental education, employment status or income; adjusting for comorbidities/habits implies adjusting for at least one of the following: comorbidities, body mass index, smoking habits, alcohol consumption or exercise habits. ${ }^{b}$ No heterogeneity computed, as there is one single study in this subgroup.

A.

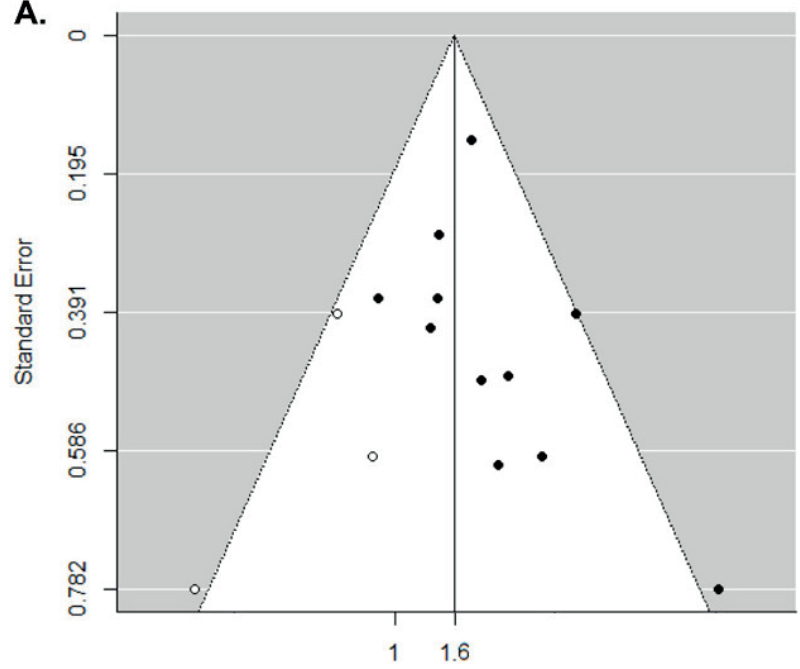

Observed Outcome
B.

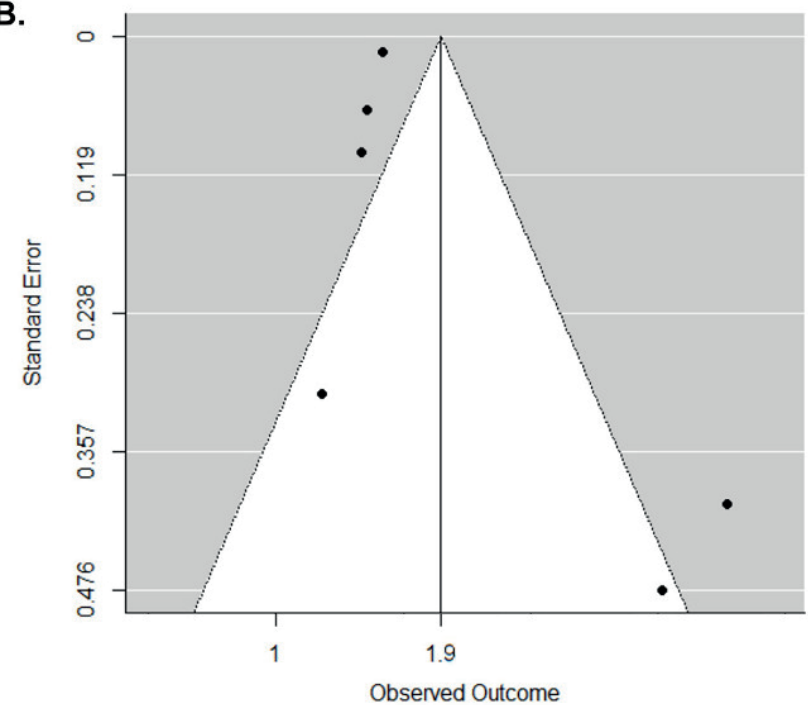

Figure 5. Funnel plots for assessment of publication bias among studies included in the meta-analysis of the association between: A) RA and the risk of depression; B) RA and risk of anxiety.

levels of pro-inflammatory cytokines, disturbance in cholinergic regulation or excessive histamine production ${ }^{(10,44,45)}$. In fact, high systemic levels of inflammatory mediators produced in the allergic process appears to have an important contribution in limbic system deregulation and depression pathogenesis ${ }^{(46)}$. On the other hand, there is a robust body of evidence showing altered circulating levels of immune cells and inflammatory mediators in patients with mental disorders. Our results are also compa- 
Table 4a. Results of the subgroup and meta-regression analyses on the association between allergic rhinitis and depression and anxiety.

\begin{tabular}{|c|c|c|c|c|c|}
\hline & \multirow[b]{2}{*}{$\begin{array}{c}\mathbf{N} \\
\text { studies }\end{array}$} & $\begin{array}{r}\text { DEPRESSI } \\
\text { Subgroup ana }\end{array}$ & is & Meta-re & yression \\
\hline & & OR $(95 \% \mathrm{CI})$ [p-value] & $\begin{array}{l}\text { Heteroge- } \\
\text { neity - } I^{2} ; \\
\text { p-value }\end{array}$ & $\begin{array}{c}\text { Univariable meta-re- } \\
\text { gression - OR ( } 95 \% \mathrm{CI}) \\
\text { [p-value] }\end{array}$ & $\begin{array}{c}\text { Multivariable meta-re- } \\
\text { gression - OR }(95 \% \mathrm{Cl}) \\
{[\mathrm{p}-\mathrm{value}]^{\ddagger}}\end{array}$ \\
\hline All studies & 21 & $1.40(1.30,1.52)[<0.001]$ & $98 \% ;<0.001$ & & \\
\hline Year of publication & 21 & $-{ }^{\dagger}$ & & $0.98(0.98-0.99)[<0.001]$ & $0.99(0.98-1.00)[0.159]$ \\
\hline Mean age & 18 & $-{ }^{+}$ & & $1.01(1.00-1.01)[0.025]$ & \\
\hline $\begin{array}{l}\text { Age group } \\
\text { Children and adolescents } \\
\text { Adults } \\
\text { Adults and children }\end{array}$ & $\begin{array}{c}4 \\
13 \\
4\end{array}$ & $\begin{array}{c}1.15(0.89,1.48)[0.290] \\
1.41(1.25,1.59)[<0.001] \\
1.62(1.40,1.88)[<0.001]\end{array}$ & $\begin{array}{c}71 \% ; 0.01 \\
75 \% ;<0.001 \\
97 \% ;<0.001\end{array}$ & $\begin{array}{l}0.75(0.60-0.94)[0.014] \\
1.07(0.84-1.35)[0.606] \\
1.25(1.08-1.46)[0.004]\end{array}$ & $\begin{array}{l}0.78(0.61-1.00)[0.054] \\
1.21(0.93-1.58)[0.161]\end{array}$ \\
\hline Percentage of females & 21 & & & $1.00(1.00-1.00)[0.955]$ & \\
\hline $\begin{array}{l}\text { Region } \\
\text { Europe } \\
\text { North America } \\
\text { Far East }\end{array}$ & $\begin{array}{c}7 \\
10 \\
4\end{array}$ & $\begin{array}{c}1.42(1.18-1.70)[<0.001] \\
1.63(1.40-1.89)[<0.001] \\
1.12(1.03-1.22)[0.007]\end{array}$ & $\begin{array}{c}85 \% ;<0.001 \\
98 \% ;<0.001 \\
24 \% ; 0.267\end{array}$ & $\begin{array}{l}0.98(0.82-1.18)[0.858] \\
1.29(1.06-1.56)[0.012] \\
0.73(0.59-0.89)[0.002]\end{array}$ & \\
\hline Percentage of asthmatics & 10 & $-{ }^{+}$ & & $0.99(0.97-1.02)[0.631]$ & \\
\hline $\begin{array}{l}\text { Percentage of patients with atopic } \\
\text { dermatitis }\end{array}$ & 8 & $-{ }^{\dagger}$ & & $1.00(0.99-1.00)[0.272]$ & \\
\hline Percentage of urban dwellers & 5 & $-^{\dagger}$ & & $0.99(0.98-1.00)[0.012]$ & \\
\hline $\begin{array}{l}\text { Method of rhinitis assessment } \\
\text { Self-report } \\
\text { Clinical diagnosis } \\
\text { Previous clinical diagnosis }\end{array}$ & $\begin{array}{c}13 \\
5 \\
3\end{array}$ & $\begin{array}{c}1.35(1.24,1.48)[<0.001] \\
2.04(1.20,3.46)[0.009] \\
1.38(1.17,1.63)[<0.001]\end{array}$ & $\begin{array}{c}97 \% ;<0.001 \\
72 \% ; 0.006 \\
98 \% ;<0.001\end{array}$ & $\begin{array}{l}0.92(0.79-1.08)[0.304] \\
1.41(1.05-1.89)[0.021] \\
0.98(0.84-1.15)[0.823]\end{array}$ & $\begin{array}{l}1.18(0.92-1.52)[0.187] \\
1.80(1.22-2.64)[0.003]\end{array}$ \\
\hline $\begin{array}{l}\text { Method of depression assessment } \\
\text { Self-report } \\
\text { Questionnaire } \\
\text { Previous clinical diagnosis }\end{array}$ & $\begin{array}{c}7 \\
11 \\
3\end{array}$ & $\begin{array}{l}1.33(1.20,1.48)[<0.001] \\
1.63(1.27,2.09)[<0.001] \\
1.38(1.17,1.63)[<0.001]\end{array}$ & $\begin{array}{c}66 \% ; 0.001 \\
69 \% ;<0.001 \\
98 \% ;<0.001\end{array}$ & $\begin{array}{l}0.92(0.79-1.07)[0.263] \\
1.15(0.96-1.39)[0.122] \\
0.98(0.84-1.15)[0.823]\end{array}$ & \\
\hline Number of good quality items & 21 & $-{ }^{+}$ & & $0.99(0.91-1.07)[0.785]$ & \\
\hline
\end{tabular}

$\mathrm{Cl}=$ Confidence interval; OR=Odds Ratio; ${ }^{\dagger}$ Subgroup analysis not performed, as this is a continuous variable; ${ }^{\ddagger}$ Residual heterogeneity: $69.8 \%$, Omnibus $\mathrm{p}$-value $<0.001$.

tible to those of meta-analyses linking chronic diseases with mood disorders. In fact, regarding depression, we found that patients with AR had 1.6 times more odds to develop depression, compared to healthy controls. This result is not dissimilar from those previously described for the association between depression and asthma (such as the meta-analysis by Lu et al., which identified a relative risk of 1.6 and the meta-analysis by Gao et al., which identified a relative risk of 1.2(142,47), as well as between depression and hypertension, cardiac disease, diabetes or chronic lung disease (meta-analytical ORs ranging from 1.3 and 2.1 $)^{(48)}$. Patients with these chronic diseases tend to be older on average than those with $A R$, which hints at the important impact of AR in young patients, also suggested by the impact of AR in work productivity ${ }^{(8)}$. Concerning anxiety, we found that patients with AR have 1.9 higher odds of developing anxiety compared to controls, similar to what has been previously described for the association between anxiety and asthma
$(\mathrm{OR}=1.8)^{(12)}$ or between anxiety and other chronic diseases, such as hypertension ${ }^{(49)}$, cardiac disease ${ }^{(50)}$, diabetes ${ }^{(51)}$ or chronic lung disease $^{(52)}$ (OR ranging from 1.2 and 1.9).

In this systematic review, we included studies with different methods of assessing AR, depression and anxiety. Presence of AR was identified by self-report in 7 studies ${ }^{(26,27,29,30,36,39,41)}$ and in these studies we need to consider the possibility of an incorrect diagnosis by a mistake with other naso-sinusal diseases such as sinusitis or non-allergic rhinitis. Some studies used a survey designed to estimate the prevalence of various health issues and which also included questions about whether AR has been diagnosed by a doctor, possibly leading to an underestimation of AR frequency $(26,27,29,30,39)$. Regarding the outcome assessment, depression was mainly detected by questionnaires or selfreport, constituting an important limitation that may result in an overestimation - Kim et al. and Zhou et al. assessed depression inquiring "Have you been diagnosed with depression by a doc- 
Table 4b. Results of the subgroup and meta-regression analyses on the association between allergic rhinitis and depression and anxiety.

\begin{tabular}{|c|c|c|c|c|}
\hline & \multirow[b]{2}{*}{$\begin{array}{c}\text { N } \\
\text { studies }\end{array}$} & \multicolumn{2}{|c|}{ ANXIETY } & Meta-regression \\
\hline & & OR (95\%CI) [p-value] & $\begin{array}{l}\text { Heteroge- } \\
\text { neity - } \mathbf{l}^{2} \\
\text { p-value }\end{array}$ & $\begin{array}{cc}\text { Univariable meta-re- } & \text { Multivariable meta-re- } \\
\text { gression - OR }(95 \% \mathrm{Cl}) & \text { gression - OR }(95 \% \mathrm{CI}) \\
\text { [p-value] } & {[p-v a l u e]^{\ddagger}}\end{array}$ \\
\hline All studies & 10 & $2.10(1.73-2.56)[<0.001]$ & $95 \% ;<0.001$ & \\
\hline Year of publication & 10 & $--^{\dagger}$ & & $1.02(0.99-1.04)[0.205]$ \\
\hline Mean age & 8 & $--^{\dagger}$ & & $0.99(0.97-1.01)[0.407]$ \\
\hline $\begin{array}{l}\text { Age group } \\
\text { Children and adolescents } \\
\text { Adults } \\
\text { Adults and children }\end{array}$ & $\begin{array}{l}1 \\
6 \\
3\end{array}$ & $\begin{array}{l}2.66(1.95-3.63)[<0.001] \\
3.61(1.87,6.98)[<0.001] \\
1.70(1.25,2.32)[<0.001]\end{array}$ & $\begin{array}{c}-\psi \\
84 \% ;<0.001 \\
99 \% ;<0.001\end{array}$ & $\begin{array}{l}1.31(0.72-2.37)[0.379] \\
1.48(0.93-2.37)[0.098] \\
0.62(0.39-0.98)[0.042]\end{array}$ \\
\hline Percentage of females & 10 & $--^{\dagger}$ & & $1.00(0.99-1.01)[0.862]$ \\
\hline $\begin{array}{l}\text { Region } \\
\text { Europe } \\
\text { North America }\end{array}$ & $\begin{array}{l}4 \\
6\end{array}$ & $\begin{array}{l}3.99(1.57-10.17)[0.004] \\
2.06(1.55-2.75)[<0.001]\end{array}$ & $\begin{array}{l}80 \% ;<0.001 \\
95 \% ;<0.001\end{array}$ & $\begin{array}{l}1.42(0.79-2.53)[0.237] \\
0.71(0.40-1.26)[0.237]\end{array}$ \\
\hline Percentage of asthmatics & 3 & $-^{\dagger}$ & & $1.02(0.95-1.11)$ [0.529] \\
\hline $\begin{array}{l}\text { Percentage of patients with ato- } \\
\text { pic dermatitis }\end{array}$ & 3 & $-^{+}$ & & $1.04(0.97-1.11)$ [0.309] \\
\hline $\begin{array}{l}\text { Method of rhinitis assessment } \\
\text { Self-report } \\
\text { Clinical diagnosis } \\
\text { Previous clinical diagnosis }\end{array}$ & $\begin{array}{l}5 \\
3 \\
2\end{array}$ & $\begin{array}{c}2.17(1.59,2.95)[<0.001] \\
7.74(4.38,13.69)[<0.001] \\
1.45(1.00,2.10)[<0.001]\end{array}$ & $\begin{array}{c}84 \% ;<0.001 \\
0 \% ; 0.88 \\
99 \% ;<0.001\end{array}$ & $\begin{array}{c}0.97(0.61-1.54)[0.892] \\
4.23(2.18-8.21)[<0.001] \\
0.54(0.33-0.87)[0.012]\end{array}$ \\
\hline $\begin{array}{l}\text { Method of depression assessment } \\
\text { Self-report } \\
\text { Questionnaire } \\
\text { Previous clinical diagnosis }\end{array}$ & $\begin{array}{l}2 \\
6 \\
2\end{array}$ & $\begin{array}{c}2.53(2.13,3.01)[<0.001] \\
3.61(1.87,6.98)[<0.001] \\
1.45(1.00,2.10)[0.05]\end{array}$ & $\begin{array}{c}0 \% ; 0.69 \\
84 \% ;<0.001 \\
99 \% ;<0.001\end{array}$ & $\begin{array}{l}1.33(0.87-2.05)[0.193] \\
1.48(0.93-2.37)[0.098] \\
0.54(0.33-0.87)[0.012]\end{array}$ \\
\hline Number of good quality items & 10 & $-{ }^{\dagger}$ & & $0.98(0.71-1.37)$ [0.923] \\
\hline
\end{tabular}

$\mathrm{Cl}=$ Confidence interval; OR=Odds Ratio; ${ }^{\dagger}$ Subgroup analysis not performed, as this is a continuous variable; ${ }^{\ddagger}$ Residual heterogeneity: $69.8 \%$, Omnibus $\mathrm{p}$-value $<0.001 ;{ }^{\Psi}$ No heterogeneity computed, as there is one single study in this subgroup.

tor?" and "How often feel depressed?", which do not constitute the best way to establish the diagnosis by possible misinterpretation of a reactive depression situation. However, in our review, sub-group analyses did not reveal differences according to the various assessment methods of AR and depression and anxiety. Particular attention must be given to the study performed by Zhou et al, the largest study included in our review. Besides being by far the study contributing with most participants, it uses a database that was designed and populated using a probability sample survey to potentially represent the entire USA population (posing even the risk of double inclusion of participants who are also assessed in other primary studies). Therefore, we performed sensitivity analysis removing the study of Zhou et al., observing similar results, with low heterogeneity. This systematic review has some limitations worth discussing. Firstly, the studies included in our meta-analyses are cross-sectional. Meta-analytical evidence on the association between other depression/anxiety and other chronic diseases (such as diabetes and hypertension) has also largely comprised cross-sectional studies as their primary studies. This hinders the establishment of a temporal relationship (and, subsequently, of causality) between exposure and outcome. Longitudinal studies investigating the association between AR and risk of depression/anxiety are scarce (we were only able to identify two of them), limiting the possibility of assessing whether AR associates with increased risk of developing depression/anxiety. However, the cohort studies identified by us are in accordance with the results of our meta-analysis, with both identifying a significant increase in risk of depression and anxiety in patients with AR. Further welldesigned cohort studies are needed in the future. Furthermore, only three studies included in this review stratified AR according to the severity or length of exposure to rhinitis symptoms ${ }^{(20,30,36)}$. Although there may be some association between the duration of symptoms and the risk of depression or anxiety, as shown by Kim et al., the underlying evidence is still scarce and not robust ${ }^{(30)}$.

In addition, no primary study complied with all items of methodological quality. None of the studies presented a sample size 
Table 5. Meta-analytical results and results of the subgroup analyses on the association between allergic rhinitis and anxiety.

\begin{tabular}{|c|c|c|c|}
\hline & \multirow[t]{2}{*}{ N studies } & \multicolumn{2}{|c|}{ Subgroup analysis } \\
\hline & & OR $(95 \% \mathrm{CI})$ [p-value] & $\begin{array}{l}\text { Heterogeneity - } \mathbf{I}^{2} ; \\
\text { p-value }\end{array}$ \\
\hline All studies & 6 & $1.91(1.21-3.02)[0.005]$ & $97 \% ; 0.002$ \\
\hline $\begin{array}{l}\text { Variables adjusted for in multivariable models a } \\
\text { Demographic variables } \\
\text { Demographic and socioeconomic variables and comorbidities/habits }\end{array}$ & $\begin{array}{l}5 \\
4\end{array}$ & $\begin{array}{l}1.52(1.48-1.55)[<0.001] \\
1.45(1.28-1.64)[<0.001]\end{array}$ & $\begin{array}{l}0 \% ; 0.114 \\
0 \% ; 0.101\end{array}$ \\
\hline $\begin{array}{l}\text { Region } \\
\text { USA }\end{array}$ & 4 & $1.45(1.28-1.64)[<0.001]$ & $0 \% ; 0.101$ \\
\hline $\begin{array}{l}\text { Age group } \\
\text { Children and adolescents } \\
\text { Adults }\end{array}$ & $\begin{array}{l}3 \\
4\end{array}$ & $\begin{array}{l}1.87(1.06-3.29)[0.031] \\
1.84(1.01-3.34)[0.044]\end{array}$ & $\begin{array}{l}71 \% ; 0.068 \\
98 \% ; 0.005\end{array}$ \\
\hline $\begin{array}{l}\text { Method of rhinitis assessment } \\
\text { Self-report } \\
\text { Clinical diagnosis }\end{array}$ & $\begin{array}{l}3 \\
3\end{array}$ & $\begin{array}{l}1.78(0.91-3.49)[0.092] \\
2.19(0.94-5.12)[0.069]\end{array}$ & $\begin{array}{l}79 \% ; 0.045 \\
89 \% ; 0.003\end{array}$ \\
\hline $\begin{array}{l}\text { Method of depression assessment } \\
\text { Self-report } \\
\text { Questionnaire } \\
\text { Previous clinical diagnosis }\end{array}$ & $\begin{array}{l}3 \\
2 \\
1\end{array}$ & $\begin{array}{l}2.15(0.90-5.16)[0.085] \\
2.23(0.60-8.21)[0.229] \\
1.52(1.48-1.56)[<0.001]\end{array}$ & $\begin{array}{l}89 \% ; 0.002 \\
82 \% ; 0.019 \\
-b\end{array}$ \\
\hline
\end{tabular}

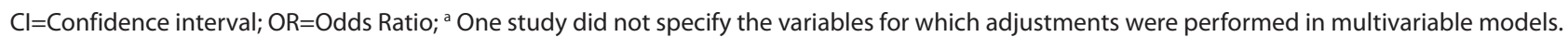
Adjusting for demographic variables implies adjusting for at least one of the following: sex, age, ethnicity, marital status or region; adjusting for socioeconomic variables implies adjusting for at least one of the following: education, parental education or income; adjusting for comorbidities/habits implies adjusting for at least one of the following: comorbidities, body mass index, smoking habits. ${ }^{\mathrm{b}}$ No heterogeneity computed, as there is one single study in this subgroup.

justification and some studies did not adjust for confounding or have valid, reliable and clearly defined outcome measures. Such methodological concerns are not unexpected findings since many of the studies were based on data collected not for the specific purpose of evaluating this association.

Another limitation concerns the heterogeneity observed in the analysis assessing the association between AR and anxiety, which can be explained, among others, by differences in the exposure and outcomes assessment methods, the use of broad definitions of depression and anxiety (rather than clinical definitions) in some primary studies and differences in participants' demographic characteristics (e.g., regarding their age). Nevertheless, no heterogeneity was observed in sugbroup analyses restricted to studies reporting results of multivariable models adjusting for a larger set of variables.

Finally, publication bias is probably present. The predominance of studies with a positive association between AR and mood disorders (as portrayed in the asymmetry of the funnel plots), suggests an overestimation of our pooled Odds Ratio. Thus, the real association between AR and depression/anxiety is probably weaker than the one obtained in this meta-analysis, as suggested by trim-and-fill analysis for the association between AR and depression (although significant associations were still observed in such analysis).

This study has also several strengths. To the best of our know- ledge, this study is the first to perform a systematic review and meta-analysis focused on the association between AR and depression and/or anxiety. Previous studies focused on atopy or the overall effect of allergic disorders without evaluating the specific effect of AR in mental health. Furthermore, our analysis comprises a profound and extensive literature research, assessing data on over 222 million participants in the AR-depression association and on over 1.7 million participants in AR-anxiety link. In an attempt to minimize the impact of publication bias, we searched three different electronic databases and complemented with search on primary studies' references. We also did not apply exclusion criteria based on the date or language of publication. Finally, we explored sources of heterogeneity through subgroup analyses and meta-regression, allowing for the identification of variables explaining across-studies differences.

\section{Conclusion}

In summary, this review supports the hypothesis that allergic diseases, probably due to a common mechanism, are associated with mental illness. In particular, our results suggest that patients with AR have higher chance of mood disorders, such as depression and anxiety. This points to the importance of enhancing awareness among clinicians on the mental comorbidities of $A R$, which should allow earlier diagnosis and possibly referral 
for psychiatric evaluation. The cross-sectional nature of included primary studies (along with the fact that some studies assessed AR and anxiety/depression by self-reporting), however, does not allow for inferring on any causal relation, nor on the directionality for the association between AR and anxiety/depression. In fact, the scarcity of longitudinal studies assessing this question is a relevant limitation - therefore, to allow the assessment of temporal associations and to diminish the impact of confounding variables, longitudinal studies are needed, preferably with a prospective design, adopting uniform definitions (with on-site AR and depression/anxiety assessment based on validated questionnaires and/or clinical diagnosis) and presenting results stratified by AR severity. In a more distant future, experimental studies may even be designed to assess whether a more adequate control of the AR also results in better control of comorbi- dities and increased patient well-being.

\section{Authorship contribution}

Data collection was a long process performed by JR, FFP and KR. Meta-analysis required the essential specialized work of BSP. The revision of the manuscript and important clinical correlations were performed by two renowned authors in the areas of ENT and Allergy, respectively, RV and JB.

\section{Conflict of interest}

The authors declare that they have no relevant conflicts of interest.

\section{Financial disclosure}

This is an unfunded project.

\section{References}

1. Bauchau V, Durham SR. Prevalence and rate of diagnosis of allergic rhinitis in Europe. Eur Resp J. 2004; 24(5): 758-764.

2. Bauchau V, Durham SR. Epidemiologica characterization of the intermittent and persistent types of allergic rhinitis. Allergy. 2005; 60(3): 350-353.

3. Prabhat D, Sholapuri D, Uchit G. Physicians Perception on Allergic Rhinitis and Its Management: A Questionnaire Based Survey. Indian J Otolaryngol Head Neck Surg. 2019; 71(Suppl 3): 2096-2105.

4. Santos CB, Pratt EL, Hanks C, McCann J, Craig TJ. Allergic rhinitis and its effect on sleep, fatigue, and daytime somnolence. Ann Allergy Asthma Immunol. 2006; 97(5): 579-586; quiz 586-579, 671.

5. Sundberg R, Torén K, Höglund D, Aberg N, Brisman J. Nasal symptoms are associated with school performance in adolescents. Adolesc Health. 2007; 40(6): 581-583.

6. Shedden A. Impact of nasal congestion on quality of life and work productivity in allergic rhinitis: findings from a large online survey. Treat Respir Med. 2005; 4(6): 439-446.

7. Bousquet J, Neukirch F, Bousquet PJ, et al. Severity and impairment of allergic rhinitis in patients consulting in primary care. Allergy Clin Immunol. 2006; 117(1): 158-162.

8. Vandenplas $O$, Vinnikov D, Blanc PD, et al Impact of Rhinitis on Work Productivity: A Systematic Review. J Allergy Clin Immunol. 2018; 6(4): 1274-1286.e1279.

9. Goodwin RD, Galea S, Perzanowski M Jacobi F. Impact of allergy treatment on the association between allergies and mood and anxiety in a population sample. Clin Exp Allergy. 2012; 42(12): 1765-1771.

10. Timonen $M$, Jokelainen J, Herva A, Zitting $P$, Meyer-Rochow VB, Rasanen P. Presence of atopy in first-degree relatives as a predictor of a female proband's depression: results from the Northern Finland 1966 Birth Cohort. J Allergy Clin Immunol. 2003; 111(6): 1249-1254.
11. Marshall PS, Colon EA. Effects of allergy season on mood and cognitive function. Ann Allergy. 1993; 71(3): 251-258

12. Lu Y, Mak KK, van Bever HP, Ng TP, Mak A, Ho RC. Prevalence of anxiety and depressive symptoms in adolescents with asthma: a meta-analysis and meta-regression. Pediatr Allergy Immunol. 2012; 23(8): 707-715.

13. Moher D, Liberati A, Tetzlaff J, Altman DG. Preferred reporting items for systematic reviews and meta-analyses: the PRISMA statement. Ann Intern Med. 2009; 151(4): 264-269, w264.

14. Higgins JP, Thomas J, Chandler J, et al. Cochrane handbook for systematic reviews of interventions: John Wiley \& Sons; 2019.

15. Lung NH, Institute B. Quality Assessment Tool for Observational Cohort and CrossSectional Studies-NHLBI, NIH. National Institutes of Health. 2014. 2015.

16. Di Pietrantonj C. Four-fold table cell frequencies imputation in meta analysis. Stat Med. 2006; 25(13): 2299-2322.

17. Sousa-Pinto B, C. DP. Estimates of table cell frequencies (raw data) from effect size measures.

18. Addolorato G, Ancona C, Capristo E, et al. State and trait anxiety in women affected by allergic and vasomotor rhinitis. J Psychosom Res. 1999; 46(3): 283-289.

19. Bahreinian S, Ball GDC, Colman I, Becker AB, Kozyrskyj AL. Depression is more common in girls with nonatopic asthma. Chest. 2011; 140(5): 1138-1145

20. Bedolla-Barajas M, Morales-Romero J, Pulido-Guillen NA, Robles-Figueroa M, Plascencia-Dominguez BR. Rhinitis as an associated factor for anxiety and depression amongst adults. Braz J Otorhinolaryngol. 2017; 83(4): 432-438.

21. Bell IR, Jasnoski ML, Kagan J, King DS Depression and allergies: survey of a nonclinical population. Psychother Psychosom. 1991; 55(1): 24-31.

22. Chen MH, Su TP, Chen YS, et al. Allergic rhinitis in adolescence increases the risk of depression in later life: a nationwide population-based prospective cohort study. J Affect Disord. 2013; 145(1): 49-53.

23. Chun $\mathrm{YH}$, Han $\mathrm{K}$, Park $\mathrm{YG}$, et al. Examining impacts of allergic diseases on psychological problems and tobacco use in Korean adolescents: the 2008-2011 Korean National Health and Nutrition Examination Survey. PLoS One. 2015; 10(4): e0125172.

24. Cuffel B, Wamboldt M, Borish L, Kennedy S, Crystal-Peters J. Economic consequences of comorbid depression, anxiety, and allergic rhinitis. Psychosomatics. 1999; 40(6): 491496.

25. Derebery J, Meltzer E, Nathan RA, et al. Rhinitis symptoms and comorbidities in the United States: burden of rhinitis in America survey. Otolaryngol Head Neck Surg. 2008; 139(2): 198-205.

26. Garg N, Silverberg Jl. Association between childhood allergic disease, psychological comorbidity, and injury requiring medical attention. Ann Allergy Asthma Immunol. 2014; 112(6): 525-532.

27. Goodwin RD. Self-reported hay fever and panic attacks in the community. Ann Allergy Asthma Immunol. 2002; 88(6): 556559.

28. Grosso A, Pesce G, Marcon A, et al. Depression is associated with poor control of symptoms in asthma and rhinitis: A population-based study. Respir Med. 2019; 155: 6-12.

29. Hurwitz EL, Morgenstern H. Cross-sectional associations of asthma, hay fever, and other allergies with major depression and lowback pain among adults aged 20-39 years in the United States. Am J Epidemiol. 1999; 150(10): 1107-1116

30. Kim DH, Han K, Kim SW. Relationship Between Allergic Rhinitis and Mental Health in the General Korean Adult Population. Allergy Asthma Immunol Res. 2016; 8(1): 49-54.

31. Kim SY, Choi SH, Kim JD, et al. Korean Youth with Comorbid Allergic Disease and Obesity 
Show Heightened Psychological Distress. Pediatr. 2019; 206: 99-104.e104.

32. Kovacs M, Stauder A, Szedmak S. Severity of allergic complaints: the importance of depressed mood. J Psychosom Res. 2003; 54(6): 549-557.

33. Lind $N$, Nordin M, Palmquist $E$, Nordin $S$. Psychological distress in asthma and allergy: the Västerbotten Environmental Health Study. Psychol Health Med. 2014; 19(3): 316323.

34. Nanda MK, LeMasters GK, Levin L, et al. Allergic Diseases and Internalizing Behaviors in Early Childhood. Pediatrics. 2016; 137(1)

35. Oh H, Koyanagi A, DeVylder JE, Stickley A. Seasonal Allergies and Psychiatric Disorders in the United States. Int J Environ Res Public Health. 2018; 15(9)

36. Roxbury CR, Qiu M, Shargorodsky J, Woodard TD, Sindwani R, Lin SY. Association Between Rhinitis and Depression in United States Adults. J Allergy Clin Immunol Pract. 2019; 7(6): 2013-2020.

37. Sato Y, Hiyoshi A, Melinder C, Suzuki C, Montgomery S. Asthma and atopic diseases in adolescence and antidepressant medication in middle age. J Health Psychol. 2018 23(6): 853-859.

38. Schmitt J, Stadler E, Kuster D, Wustenberg EG. Medical care and treatment of allergic rhinitis: a population-based cohort study based on routine healthcare utilization data. Allergy. 2016; 71 (6): 850-858

39. Shin JH, Roh $\mathrm{D}$, Lee $\mathrm{DH}$, et al. Allergic rhinitis and rhinosinusitis synergistically compromise the mental health and health-related quality of life of Korean adults: A nationwide population-based survey. PLoS One. 2018, 13(1): e0191115.
40. Tas HI, Caglar O. The role of anxious temperament in patients with allergic rhinitis. Saudi Med J. 2019; 40(1): 45-51.

41. Zhou S, Hur K, Shen J, Wrobel B. Impact of sinonasal disease on depression, sleep duration, and productivity among adults in the United States. Laryngoscope Investig Otolaryngol. 2017; 2(5): 288-294

42. Lu Z, Chen L, Xu S, et al. Allergic disorders and risk of depression: A systematic review and meta-analysis of 51 large-scale studies. Ann Allergy Asthma Immunol. 2018; 120(3): 310-317.e312

43. Jiang $M$, Qin P, Yang X. Comorbidity between depression and asthma via immune-inflammatory pathways: a metaanalysis. J Affect Disord. 2014; 166: 22-29.

44. Wamboldt MZ, Hewitt JK, Schmitz S, et al, Familial association between allergic disorders and depression in adult Finnish twins. Am J Med Genet. 2000; 96(2): 146-153.

45. Van Lieshout RJ, Bienenstock J, MacQueen GM. A review of candidate pathways underlying the association between asthma and major depressive disorder. Psychosom Med. 2009; 71(2): 187-195.

46. Shin J, Choi Y, Park EC, et al. Psychiatry outpatient visits by atopic dermatitis patients varying in the complexity of their prescriptions: A nationwide cohort study conducted from 2005 to 2013. Medicine (Baltimore). 2016; 95(49): e5411.

47. Gao YH, Zhao HS, Zhang FR, et al. The Relationship between Depression and Asthma: A Meta-Analysis of Prospective Studies. PloS one. 2015; 10(7): e0132424.

48. Huang CQ, Dong BR, Lu ZC, Yue JR, Liu QX Chronic diseases and risk for depression in old age: a meta-analysis of published literature. Ageing Res Rev. 2010; 9(2): 131-141.
49. Pan Y, Cai W, Cheng Q, Dong W, An T, Yan J. Association between anxiety and hypertension: a systematic review and meta-analysis of epidemiological studies. Neuropsychiatr Dis Treat.. 2015; 11: 1121-1130.

50. Roest AM, Martens EJ, Denollet J, de Jonge P. Prognostic association of anxiety post myocardial infarction with mortality and new cardiac events: a meta-analysis. Psychosom Med. 2010; 72(6): 563-569.

51. Smith KJ, Béland $M$, Clyde $M$, et al Association of diabetes with anxiety: a systematic review and meta-analysis. $J$ Psychosom Res. 2013; 74(2): 89-99.

52. Eisner MD, Blanc PD, Yelin EH, et al. Influence of anxiety on health outcomes in COPD. Thorax. 2010; 65(3): 229-234.

\section{J. Rodrigues}

Unit of Anatomy

Department of Biomedicine

Faculty of Medicine

University of Porto

Al. Professor Hernâni Monteiro

4200-319 Porto

Portugal

Tel: (+351) 225513616

Fax: (+351) 225513617

E-mail address:

jorge.rods@hotmail.com 


\section{SUPPLEMENTARY MATERIAL}

Supplementary Table 1. Meta-analytical results and results of the subgroup analyses on the association between allergic rhinitis and depression excluding the study performed by Zhou et al.

\begin{tabular}{|c|c|c|c|}
\hline & \multirow[t]{2}{*}{ N studies } & \multicolumn{2}{|c|}{ Subgroup analysis } \\
\hline & & OR (95\%CI) [p-value] & $\begin{array}{c}\text { Heterogeneity - } \text { I' }^{\mathbf{2}} \\
\text { p-value }\end{array}$ \\
\hline All studies & 10 & $1.66(1.34-2.04)[<0.001]$ & $0 \% ; 0.300$ \\
\hline $\begin{array}{l}\text { Variables adjusted for in multivariable models a } \\
\text { Demographic variables } \\
\text { Demographic and socioeconomic variables } \\
\text { Demographic variables and comorbidities/habits } \\
\text { Demographic and socioeconomic variables and comorbidities/habits }\end{array}$ & $\begin{array}{l}9 \\
6 \\
7 \\
5\end{array}$ & $\begin{array}{l}1.63(1.32-2.02)[<0.001] \\
1.93(1.30-2.87)[0.001] \\
1.69(1.11-2.57)[0.014] \\
1.95(1.20-3.18)[0.007]\end{array}$ & $\begin{array}{l}0 \% ; 0.254 \\
16 \% ; 0.236 \\
35 \% ; 0.127 \\
33 \% ; 0.148\end{array}$ \\
\hline $\begin{array}{l}\text { Region } \\
\text { USA } \\
\text { Europe } \\
\text { Far East }\end{array}$ & $\begin{array}{l}5 \\
2 \\
2\end{array}$ & $\begin{array}{l}1.61(0.96-2.71)[0.073] \\
2.02(1.09-3.73)[0.025] \\
1.43(0.77-2.65)[0.255]\end{array}$ & $\begin{array}{c}34 \% ; 0.143 \\
59 \% ; 0.118 \\
0 \% ; 0.620\end{array}$ \\
\hline $\begin{array}{l}\text { Age group } \\
\text { Children and adolescents } \\
\text { Adults }\end{array}$ & $\begin{array}{l}3 \\
7\end{array}$ & $\begin{array}{l}1.52(1.15-2.02)[0.031] \\
1.61(1.13-2.29)[0.009]\end{array}$ & $\begin{array}{c}4 \% ; 0.423 \\
19 \% ; 0.347\end{array}$ \\
\hline $\begin{array}{l}\text { Method of rhinitis assessment } \\
\text { Self-report } \\
\text { Clinical diagnosis }\end{array}$ & $\begin{array}{l}6 \\
4\end{array}$ & $\begin{array}{l}1.44(1.01-2.05)[0.044] \\
1.95(1.32-2.87)[0.001]\end{array}$ & $\begin{array}{c}0 \% ; 0.226 \\
23 \% ; 0.423\end{array}$ \\
\hline $\begin{array}{l}\text { Method of depression assessment } \\
\text { Self-report } \\
\text { Questionnaire } \\
\text { Previous clinical diagnosis }\end{array}$ & $\begin{array}{l}4 \\
5 \\
1\end{array}$ & $\begin{array}{l}1.59(1.02-2.49)[0.043] \\
1.48(1.04-2.09)[0.028] \\
1.61(1.20-2.15)[0.001]\end{array}$ & $\begin{array}{l}0 \% ; 0.201 \\
0 \% ; 0.298 \\
\text {-b }\end{array}$ \\
\hline
\end{tabular}

$\mathrm{Cl}=$ Confidence interval; OR=Odds Ratio; ${ }^{\text {a }}$ One study did not specify the variables for which adjustments were performed in multivariable models. Adjusting for demographic variables implies adjusting for at least one of the following: sex, age, ethnicity, marital status or region; adjusting for socioeconomic variables implies adjusting for at least one of the following: education, parental education, employment status or income; adjusting for comorbidities/habits implies adjusting for at least one of the following: comorbidities, body mass index, smoking habits, alcohol consumption or exercise habits. ${ }^{b}$ No heterogeneity computed, as there is one single study in this subgroup. 